\title{
Electrocardiography versus Echocardiography for assessment of left ventricular hypertrophy in ischemic heart disease patients with and without cardiovascular risk factors \\ Mansour Mohammed Moustafa, Abdel Aziz Rezk Shredah, Kamal Ahmed Marghany, Ahmed \\ Yahya Sayed Zakaria* \\ Department of Cardiology, Faculty of Medicine, Al-Azhar University \\ *Corresponding author: Ahmed Yahya Sayed Zakaria, Mobile: 01122459207; Email: cardiologist_yahya@yahoo.com
}

\begin{abstract}
Background: it is well documented that left ventricular hypertrophy (LVH) detected by 12-lead electrocardiography or echocardiography is a major risk factor for cardiovascular morbidity and mortality in cohorts ranging from the general population to those with established cardiovascular disease, including coronary artery disease (CAD).
\end{abstract}

Objectives: aims of this study were to detect prevalence of LVH in CAD patients by standard echocardiography by measuring LVM indexed to body surface area and to test the sensitivity and specificity of new ECG criteria, Peugero-Lo Prosti criteria, for detection of left ventricular hypertrophy and comparing it with other ECG criteria to diagnose LVH.

Patients and Methods: This observational cross sectional study was conducted at El-Hussein University Hospital and Minia Health Insurance Hospital during the period from July 2016 to June 2017, the study involved 230 patients of either sex, and referred for Echocardiography department to perform 2D transthoracic echocardiography.

Results: In our study, we founded that firstly, the echo-LVH is prevalent in CAD patient (41.5\%) regardless the presence of other cardiovascular risk factors. Moreover, our results showed that, the prevalence of echoLVH is significantly higher in patients with CAD and hypertension, than in patients with CAD only (54\% Vs. 32\%). Secondly, the Peguero-Lo Prosti criteria has a higher sensitivity (61.4\%) for detecting LVH among the patients with CAD than Sokolow-Lyon criteria (26.5\%), Cornell voltage criteria (32.5\%) and Romhilt Estes point score (41\%) considering LVMI by echocardiography as reference standard.

Conclusion: the prevalence of echocardiographic LVH in CAD patient is high regardless the presence of other cardiovascular risk factors. Overall the present study shows that, Peguero-Lo Presti criteria has higher sensitivity and specificity in the ECG diagnosis of LVH compared to Sokolow-Lyon criteria, Cornell voltage criteria and Romhilt-Estes point score system considering LV mass index by 2D Echocardiography as reference standard.

Keywords: Left ventricular hypertrophy, Coronary artery disease, ECG, ECHO

\section{INTRODUCTION}

It is well documented that left ventricular hypertrophy (LVH) detected by 12-lead electrocardiography or echocardiography is a major risk factor for cardiovascular morbidity and mortality in cohorts ranging from the general population to those with established cardiovascular disease, including coronary artery disease $(\mathrm{CAD})^{(\mathbf{1})}$.

Coronary artery disease can play a role in the pathogenesis of $\mathrm{LVH}$, as the normal myocardium attempts to compensate for the ischemic or infarcted tissue ${ }^{(2)}$.

Recent evidence suggests that left ventricular hypertrophy ( $\mathrm{LVH})$ is an important cause of cardiac death in patients with CAD. However, there is limited data about detection and significant of LVH in such population ${ }^{(3)}$.
The importance of detecting LVH in CAD patients is based on several reasons. Firstly, in CAD patients that the relative risk of cardiac death conferred by LVH was 2.14, 2.4 and 2.1 after adjustment for other factors including hypertension and the number of coronary vessels affected. Secondly, there is now strong evidence to suggest that regression of LVM is associated with improved prognosis in hypertensive patients. Thirdly, a hypothetical analysis suggests that identifying and regressing $\mathrm{LVH}$ in normotensive patients with angina should be worthwhile and cost-effective (4).

Several electrocardiographic (ECG) criteria have previously been proposed to diagnose $\mathrm{LVH}$, with modest differences in the 
degree of accuracy among them and that suggests lack of consensus and often leads to confusion among clinicians ${ }^{(5)}$.

The well-recognized limited sensitivity of any one ECG LVH criterion as compared with imaging modalities has been put forward as a limitation of ECG-dependent approaches to $\mathrm{LVH}$ diagnosis, despite findings that imaging and ECG methods appear to similarly track prognosis and may provide complimentary information ${ }^{(6)}$.

\section{AIMS OF THE WORK}

Firstly, to detect prevalence of LVH in CAD patients by standard echocardiography by measuring LVM indexed to body surface area. Secondly, to test the sensitivity and specificity of new ECG criteria, Peugero-Lo Prosti criteria, for detection of $\mathrm{LVH}$ and comparing it with other ECG criteria to diagnose left ventricular hypertrophy.

\section{PATIENTS AND METHODS Patient:}

The present study included 230 patients referred for echocardiography in Cardiology department, at El-Hussein University Hospital and Minia Health Insurance Hospital during the period from June 2016 to July 2017.

The patients were divided into two groups, the first group (Group I) included 200 patients with history of CAD and the presence of angiographically proven CAD (more than $50 \%$ reduction in the cross-sectional diameter of a left main trunk or $70 \%$ reduction in the cross-sectional diameter of a major coronary artery).

The second group (Group II) is a control group included 30 healthy persons.

The group (I) was further divided into two subgroups: (A) Left ventricular hypertrophy (LVH) group and (B) Non-Left ventricular hypertrophy (non-LVH) group.

Exclusion criteria: Reduced LV ejection fraction (EF) on echocardiography $(\mathrm{EF}<50 \%)$. Bundle branch block. Valvular heart disease. Congenital heart disease. Constrictive cardiomyopathy. Hypertrophic cardiomyopathy. Atrial fibrillation or flutter. Wolff Parkinson-White syndrome.

\section{Method:}

All patients were subjected to the following: Informal consent. History taking.
Clinical General physical examination of the patients. Laboratory investigation; $\mathrm{CBC}$, HbA1C, Serum Creatinine, Serum Uric acid, and Lipogram. A standard 12- lead resting electrocardiography: A standard 12 lead ECG will be recorded. The machine will be calibrated before recording ECG with paper speed at $25 \mathrm{~mm} / \mathrm{sec}$ and amplitude of stylus deflection at $1 \mathrm{mV} / \mathrm{cm}$. Sokolow-Lyon (7) criteria, Cornell ${ }^{(8)}$ voltage criteria, Romhilt Estes ${ }^{(9)}$ point score and Peguero-Lo Presti ${ }^{(5)}$ criteria were used to diagnose LVH.

Sokolow-Lyon criteria: $(\mathrm{S}$ in $\mathrm{V} 1+\mathrm{R}$ in $\mathrm{V} 5$ or $\mathrm{V} 6 \geq 35 \mathrm{~mm})^{(7)}$.

Cornell voltage criteria: (In men: SV3 $+\mathrm{RaVL}>28 \mathrm{~mm}$, in women: $\mathrm{SV} 3$ + $\mathrm{RaVL}>20 \mathrm{~mm})^{\left({ }^{(8)}\right.}$.

Romhilt Estes point score: In the present study a score of $=5$ points will be considered as $\mathrm{LVH}^{(9)}$.

\section{Table (1): Romhilt Estes point score}

\begin{tabular}{|l|l|}
\hline $\begin{array}{l}\text { Any limb lead 'R' wave or ' } \mathrm{S} \text { ' wave } \geq \\
2.0 \mathrm{mV}\end{array}$ & 3 Points \\
\hline $\mathrm{SV} 1$ or $\mathrm{SV} 2 \geq 3.0 \mathrm{mV}$ & 3 Points \\
\hline $\mathrm{RV} 5$ to RV6 $\geq 3.0 \mathrm{mV}$ & 3 Points \\
\hline $\begin{array}{l}\text { ST-T wave abnormality (no digitalis } \\
\text { therapy) }\end{array}$ & 3 Points \\
\hline $\begin{array}{l}\text { ST-T wave abnormality (digitalis } \\
\text { therapy) }\end{array}$ & 1 Points \\
\hline P terminal force in $\mathrm{V} 1>4 \mathrm{mV}-\mathrm{msec}$ & 3 Points \\
\hline Left axis deviation & 1 Points \\
\hline $\begin{array}{l}\text { Intrinsicoid deflection in } \mathrm{V} 5 \text { or } \mathrm{V} 6 \geq 50 \\
\text { msec }\end{array}$ & 1 Points \\
\hline
\end{tabular}

Peguero-Lo prosti criteria: Using the PR segment as baseline, the tallest $\mathrm{R}$ and the deepest $S$ wave in all the precordial and limb leads were recorded. The largest complex was selected if voltage differences within the same lead were present. The Peguero Lo-Presti criteria was calculated by adding SD to the $\mathrm{S}$ amplitude in V4 $\left(\mathrm{S}_{\mathrm{D}}+\mathrm{SV} 4\right)$. Cutoff values of $\mathrm{S}_{\mathrm{D}}+\mathrm{SV} 4 \geq 2.3 \mathrm{mV}$ for female subjects and $\geq 2.8$ $\mathrm{mV}$ for male subjects were considered positive for LVH based on the recent study by Peguero et al. ${ }^{(5)}$ in cases in which the $S_{D}$ was found in lead V4, the $\mathrm{S}$ wave amplitude was doubled to obtain the value $S_{D}+S V 4$.

\section{Echocardiography}

Using 2-D echocardiogram as a guideline M-mode recording obtained in parasternal long axis 
view. Left ventricular posterior wall thickness (LVPWT), left ventricular internal diameter (LVID) and interventricular septal thickness (IVS), were measured.

All measurements should be performed at the end of diastole (the frame before mitral valve closure or the frame in the cardiac cycle in which the ventricular dimension or volume is largest). Left ventricular mass index was calculated using cube formula:

LVM $=0.8 \mathrm{X} 1.04 \mathrm{X} \quad[(\mathrm{IVS}+$ LVID + LVPWT $^{3}-$ LVID $^{3}$ ] +0.6 g.

LVM was indexed to body surface area to calculate left ventricular mass index (LVMI).

Reference upper limits of normal LV mass index are $95 \mathrm{~g} / \mathrm{m}^{2}$ in women and $115 \mathrm{~g} / \mathrm{m}^{2}$ in men ${ }^{(\mathbf{1 0})}$.

Finally, calculation of relative wall thickness (RWT) with the formula:

(2X posterior wall thickness)/ (LV internal diameter at end diastole)

A value of $>0.42$ was defined as increased RWT. Left ventricular geometry was classified as normal, concentric remodeling, eccentric $\mathrm{LVH}$, or concentric $\mathrm{LVH}$, based on LVM and RWT. Normal LV geometry was defined as normal LVM and normal RWT. Concentric remodeling was defined as normal LVM and increased RWT. Eccentric LVH was defined as increased LVM and normal RWT. Concentric LVH was defined as increased LVM and increased RWT ${ }^{(\mathbf{1 0})}$.

\section{RESULTS}

Table (2) demonstrates the characteristics of the study population. The CAD population consisted of predominantly male patients with mean age of 59.8 years (Graph 1). About $42.5 \%$ of these patients had a history of hypertension.

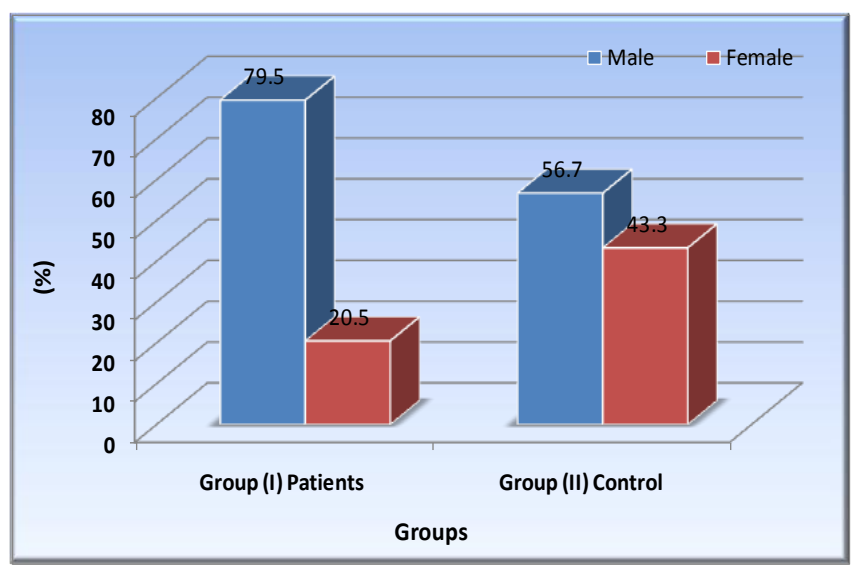

Figure (1): Distribution of patients according to sex.

Table (2): Patient characteristics (mean \pm SD) of 230 subjects in both patient and control groups.

\begin{tabular}{|c|c|c|c|}
\hline Variable & $\begin{array}{c}\text { Group (I) Patients } \\
(\mathrm{N}=200) \text { mean } \pm(\mathrm{SD})\end{array}$ & $\begin{array}{l}\text { Group (II) Control } \\
(\mathrm{N}=30) \text { mean } \pm(\mathrm{SD})\end{array}$ & $\begin{array}{c}\text { P-value } \\
\text { Sig. }\end{array}$ \\
\hline Age (year) $( \pm$ SD) & $59.8 \pm(8.6)$ & $38.4 \pm(8.5)$ & $<0.01 * *$ \\
\hline Males (\%) & 79.5 & 56.7 & $<0.01 * *$ \\
\hline Body mass index (BMI) $\left(\mathrm{Kg} / \mathrm{m}^{2}\right)$ & $31.1 \pm(4.9)$ & $28.0 \pm(3.2)$ & $<0.01 * *$ \\
\hline Body surface area (BSA) $\left(\mathrm{m}^{2}\right)$ & $2.05 \pm(0.17)$ & $1.98 \pm(0.16)$ & $0.03^{*}$ \\
\hline Systolic blood pressure (mmHg) & $129.8 \pm(19.2)$ & $113.3 \pm(10.7)$ & $<0.01 * *$ \\
\hline Diastolic blood pressure (mmHg) & $81.8 \pm(11.3)$ & $68.7 \pm(7.6)$ & $<0.01 * *$ \\
\hline Hemoglobin (g/dL) & $13.5 \pm(1.5)$ & $14.1 \pm(2.0)$ & $0.06^{\mathrm{NS}}$ \\
\hline Creatinine (mg/dl) & $0.94 \pm(0.08)$ & $0.75 \pm(0.06)$ & $<0.01 * *$ \\
\hline History of hypertension (\%) & 42.5 & 0 & $<0.01 * *$ \\
\hline History of type 2 diabetes (\%) & 23 & 0 & $<0.01 * *$ \\
\hline History of hypercholesterolemia (\%) & 65.5 & 10 & $<0.01 * *$ \\
\hline Current smokers (\%) & 34 & 36 & $0.77^{\mathrm{NS}}$ \\
\hline Ex-smoker (\%) & 10.5 & 0 & $0.05^{*}$ \\
\hline Previous CABG (\%) & 22 & 0 & $<0.01 * *$ \\
\hline Previous percutaneous coronary intervention (\%) & 76 & 0 & $<0.01 * *$ \\
\hline Previous MI (\%) & 27 & 0 & $<0.01 * *$ \\
\hline
\end{tabular}

T-test and Chi-square test were used. ** Significant (P.<0.01). NS: Not significant.

Table (3): Patient characteristics (mean \pm SD) classified according to presence of absence of left ventricular hypertrophy $(\mathrm{LVH})$ indexed to body surface area. 


\begin{tabular}{|c|c|c|c|}
\hline Variable & $\begin{array}{l}\mathrm{LVH}(\mathrm{N}=83) \\
\text { mean } \pm(\mathrm{SD})\end{array}$ & $\begin{array}{c}\text { No LVH }(\mathbf{N}=117) \\
\text { Mean } \pm(\text { SD })\end{array}$ & P.value(Sig.) \\
\hline Age (year) $( \pm$ SD) & $59.7 \pm(8.1)$ & $59.9 \pm(9.0)$ & $0.93^{\mathrm{NS}}$ \\
\hline Male (\%) & $68.7 \%$ & $87.2 \%$ & $<0.01 * *$ \\
\hline Body mass index $(\mathrm{BMI})\left(\mathrm{Kg} / \mathrm{m}^{2}\right)$ & $31.1 \pm(4.5)$ & $30.9 \pm(5.2)$ & $0.75^{\mathrm{NS}}$ \\
\hline Body surface area $\left(\right.$ BSA) $\mathbf{m}^{2}$ & $2.04 \pm(0.19)$ & $2.06 \pm(0.17)$ & $0.42^{\mathrm{NS}}$ \\
\hline Systolic blood pressure $(\mathrm{mmHg})$ & $135.9 \pm(19.4)$ & $125.3 \pm(17.8)$ & $<0.01 * *$ \\
\hline Diastolic blood pressure (mmHg) & $84.7 \pm(11.9)$ & $79.8 \pm(10.5)$ & $<0.01 * *$ \\
\hline History of hypertension (\%) & 55.4 & 33.3 & $<0.01 * *$ \\
\hline History of type 2 diabetes (\%) & 25.3 & 21.4 & $0.51^{\mathrm{NS}}$ \\
\hline History of myocardial infarction (\%) & 25.3 & 27.4 & $0.74^{\mathrm{NS}}$ \\
\hline Previous CABG (\%) & 28.9 & 17.1 & $0.04 *$ \\
\hline Previous percutaneous coronary intervention (\%) & 68.7 & 81.2 & $0.04 *$ \\
\hline Current smoker $(\%)$ & 18.1 & 45.3 & $<0.01 * *$ \\
\hline Ex. Smoker (\%) & 13.3 & 8.5 & $0.88^{\mathrm{NS}}$ \\
\hline History of hypercholesterolemia (\%) & 66.3 & 55 & $0.84^{\mathrm{NS}}$ \\
\hline Createnine (mg/dl) & $0.98 \pm(0.08)$ & $1.03 \pm(0.09)$ & $<0.01 * *$ \\
\hline Hemoglobin (g/dl) & $13.7 \pm(2.4)$ & $13.5 \pm(2.7)$ & $0.58^{\mathrm{NS}}$ \\
\hline
\end{tabular}

T-test and Chi-square test were used. **Significant (P.<0.01). NS: Not significant.

The LVMI was obtained in all patient in all patients in group (I) $(\mathrm{n}=200)$ and the proportion of patients with LVH was $41.5 \%$ (83/200) when indexed to BSA (cutoff $>95 \mathrm{~g} / \mathrm{m}^{2}$ in women and $>115$ $\mathrm{g} / \mathrm{m}^{2}$ in men). And the patient characteristics according to presence or absent of left ventricular hypertrophy $(n=200)$ indexed to body surface area are listed in table (3).

Table (4): Prevalence of Echocardiographic LVH.

\begin{tabular}{|l|c|c|c|}
\hline & $\begin{array}{c}\text { Group (I) patients } \\
(\mathbf{n = 2 0 0})\end{array}$ & $\begin{array}{c}\text { Hypertensive patients } \\
(\mathbf{n = 8 5})\end{array}$ & $\begin{array}{c}\text { Non hypertensive } \\
\text { patient }(\mathbf{n = 1 1 5})\end{array}$ \\
\hline $\begin{array}{l}\text { LVM indexed to BSA } \\
\text { Overall prevalence of LVH }\end{array}$ & $41.5 \%$ & $54.1 \%$ & $32.2 \%$ \\
\hline
\end{tabular}

Prevalence of LVH based on measuring LVM indexed to BSA using 2D-echocardiography (cutoff $>95 \mathrm{~g} / \mathrm{m}^{2}$ in women and $>115 \mathrm{~g} / \mathrm{m}^{2}$ in men) is $41.5 \%$ (83/200) in group (I) (Table 4), and $54 \%$ (46/85) in hypertensive patients and 32\% (37/115) in the non-hypertensive patients (Graph 2).

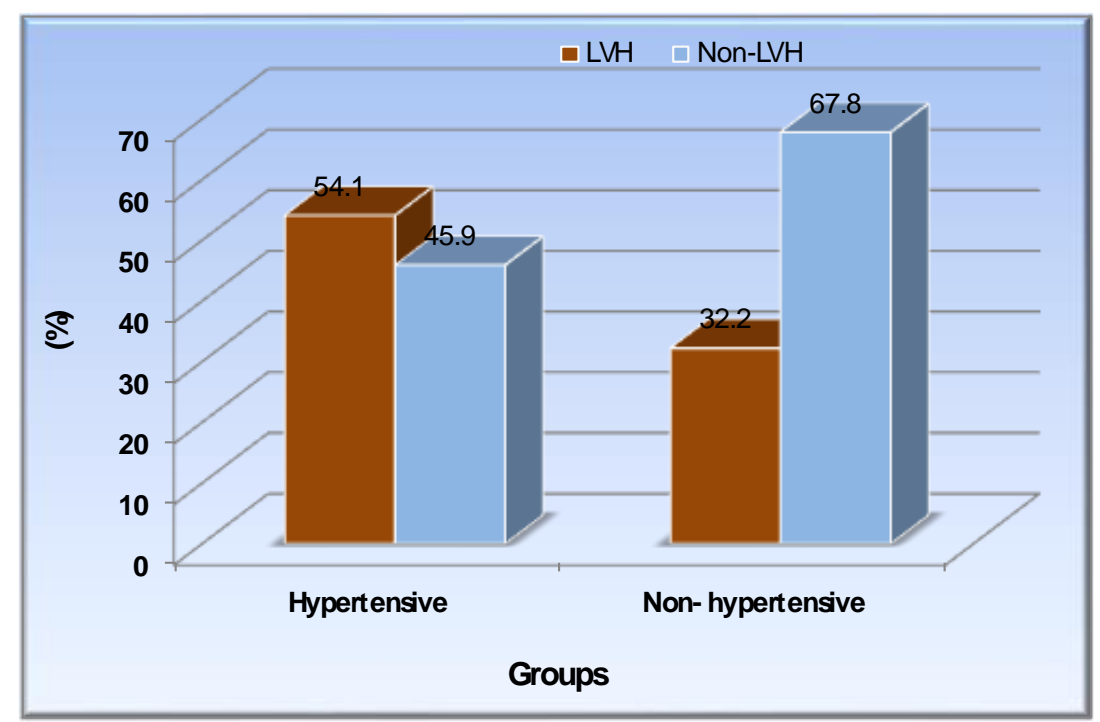

Figure (2): Prevalence of echocardiographic LVH among hypertensive and non-hypertensive patients.

Table (5): Prevalence of LVH based on four assessed ECG criteria among both patients and control groups. 


\begin{tabular}{|l|c|c|c|}
\hline \multicolumn{1}{|c|}{ Criterion } & $\begin{array}{c}\text { Group (I) Patients } \\
(\mathbf{N = 2 0 0})\end{array}$ & $\begin{array}{c}\text { Group (II) Control } \\
(\mathbf{N = 3 0 )}\end{array}$ & P. value (Sig.) \\
\hline Sokolow-Lyon (\%) & 12 & 20 & $0.22^{\mathrm{NS}}$ \\
\hline Cornell voltage (\%) & 15 & 10 & $0.46^{\mathrm{NS}}$ \\
\hline Romhilt Estes point score (\%) & 28 & 10 & $0.04^{*}$ \\
\hline Peguero-Lo presti (\%) & 33 & 16.6 & $0.12^{\mathrm{NS}}$ \\
\hline
\end{tabular}

Chi-square test was used. ${ }^{* *}$ Significant $(\mathrm{P} .<0.01) .{ }^{*}$ Significant $(\mathrm{P} .<0.05)$. NS: Not significant.

Based on Peguero-Lo Prosti ${ }^{(5)}$ criteria, 30.5\% (61/200) of the patients in group (I) w,,vvere diagnosed as LVH. Based on Sokolow-Lyon ${ }^{(7)}$ criteria, $12 \%$ (24/200) of the patients in group (I) were diagnosed as LVH. Based on Cornell voltage ${ }^{(8)}$ criteria, $15 \%$ (30/200) of the patients in group (I) were diagnosed as LVH. Based on Romhilt-Estes ${ }^{(9)}$ point score system, $28 \%(56 / 200)$ of the patients in group (I) were diagnosed as LVH (Table 5).

Table (6): The ability of ECG criteria to detect echo-LVH indexed to BSA in group (I) (n=200).

\begin{tabular}{|l|c|c|c|}
\hline \multicolumn{1}{|c|}{ Criterion } & $\begin{array}{c}\text { Sensitivity } \\
(\boldsymbol{\%})\end{array}$ & $\begin{array}{c}\text { Specificity } \\
(\boldsymbol{\%})\end{array}$ & $\begin{array}{c}\text { P. value } \\
\text { Sig. }\end{array}$ \\
\hline Sokolow-Lyon $^{(7)}$ & 26.5 & 92.3 & $<0.01^{* *}$ \\
\hline Cornell voltage $^{(\mathbf{8})}$ & 32.5 & 97.4 & $<0.01^{* *}$ \\
\hline Romhilt Estes point score $^{(\mathbf{9})}$ & 41 & 81.2 & $<0.01^{* *}$ \\
\hline Peguero-Lo presti $^{(5)}$ & 55.4 & 83 & $<0.01^{* *}$ \\
\hline
\end{tabular}

Chi-square test was used. ** Significant $($ P. $<0.01)$.

The sensitivity and the specificity of various ECG-LVH criteria: 46 patients out of 83 patients with echo-LVH were diagnosed as LVH based on Peguero-Lo Prosti criteria with sensitivity of (55.4\%) and specificity of (87.2\%). 22 patients out of 83 patients with echo-LVH were diagnosed as LVH based on Sokolow-Lyon criteria, with sensitivity of (26.5\%) and specificity (92.3\%). 27 patients out of 83 patients with echo-LVH were diagnosed as LVH based on Cornell voltage criteria, with sensitivity of $(32.5 \%)$ and specificity of (97.4\%). 34 patients out of 83 patients with echo-LVH were diagnosed as LVH based on Romhilt-Estes point score system, with sensitivity of (41\%) and specificity $(81.2 \%)$ (Table 6).

Table (7): The distribution of four geometric patterns in group (I) population ( $\mathrm{n}=200)$.

\begin{tabular}{|l|c|}
\hline \multicolumn{1}{|c|}{ LV Geometry } & \multicolumn{1}{|c|}{$\begin{array}{c}\text { Group (I) patients } \\
(\mathbf{n = 2 0 0})(\%)\end{array}$} \\
\hline Normal & 36.5 \\
\hline Concentric remodeling & 22 \\
\hline Eccentric LVH & 18.5 \\
\hline Concentric LVH & 23 \\
\hline
\end{tabular}

Chi-square test was used. ${ }^{* *}$ Significant $($ P. $<0.01)$.

The distribution of geometric patterns was $36.5 \%, 22 \%, 18.5 \%, 23 \%$ for normal, concentric remodeling, eccentric $\mathrm{LVH}$, and concentric LVH respectively (Table 7).

\section{DISCUSSION}

In our study, we founded that firstly, the echo- $\mathrm{LVH}$ is prevalent in $\mathrm{CAD}$ patient $(41.5 \%)$ regardless the presence of other cardiovascular risk factors. Moreover, our results showed that, the prevalence of echoLVH is significantly higher in patients with CAD and hypertension, than in patients with CAD only (54\% Vs. 32\%). Secondly, the Peguero-Lo Prosti criteria has a higher sensitivity (61.4\%) for detecting $\mathrm{LVH}$ among the patients with CAD than Sokolow-Lyon criteria $(26.5 \%)$, Cornell voltage criteria
(32.5\%) and Romhilt Estes point score (41\%) considering LVMI by echocardiography as reference standard. While Peguero-Lo Prosti maintaining higher specificity $(87.2 \%)$ in diagnosis of LVH in these patients compared to Sokolow-Lyon criteria (92.3\%), Cornell voltage criteria $(97.4 \%)$ and Romhilt-Estes point score system $(81.2 \%)$.

Also, the distribution of geometric pattern was $36.5 \%, 22 \%, 18.5 \%, 23 \%$ for normal, concentric remodeling, eccentric LVH, and concentric LVH respectively. 
These results add to our knowledge about the prevalence and determinants of LVH in CAD patients. Several previous studies have described the LVH in a specific patient group of CAD by using available surrogate markers.

As regards the prevalence of $\mathrm{LVH}$ in CAD patient, our results correlate with the study of Ghali et al. ${ }^{(11)}$ who evaluated 785 subjects, most of whom were black and had hypertension. Left ventricular hypertrophy, based on left ventricular mass corrected for body surface area, was present in 194 of 381 patients $(51 \%)$ with coronary artery disease Thus, further studies including other ethnic groups and reporting up-to-date information will be helpful in this setting.

In the LIFE study, by Zabalgoitia et al. (12) echocardiograms were recorded in 963 hypertensive patients (mean age $66+-7$ years, $41 \%$ women) with electrocardiographic LV hypertrophy, and divided into 149 with and 814 without clinical (prior myocardial infarction or angina pectoris) or electrocardiographic (Minnesota codes 1.1, 1.2) evidence of CAD. Patients with CAD had larger LV internal dimensions, increased LV mass.

Our results also correlate with East et al. (13) which studied records of 2461 patients (19\% black, $42 \%$ women) diagnosed with $\mathrm{CAD}$ at cardiac catheterization. Left ventricular hypertrophy was defined using standard echocardiographic measures. LVH was defined in $35 \%$ of CAD population in this study. Patients with LVH were slightly older (68 vs. 65 years) and more likely and more likely to have hypertension ( $75 \%$ vs. $61 \%$ ), diabetes (39\% vs. $31 \%$ ), and peripheral vascular disease (25\% vs. $20 \%$ ) than patients without LVH.

Also, Ang et al. ${ }^{(14)}$ further analyzed this problem. They evaluated the prevalence of LVH in 267 white patients with stable, treated angina and its relationship with blood pressure (BP) at the time of the study (19 months after coronary angiography). Left-ventricular hypertrophy, defined as a left-ventricular mass index (LVMI) _ $115 \mathrm{~g} / \mathrm{m} 2$ in men and _95 g/m2 in women, was present in $73 \%$ of subjects. When LVH was defined according to other cutoff values, its prevalence was $50(75 \%)$. Multiple logistic regression analysis showed that a history of hypertension, body mass index, and age were independently related to $\mathrm{LVH}$. Ang et al. reported that $62 \%$ of LVH patients had non hypertensive blood pressure ${ }^{(\mathbf{1 4})}$.
Anwar et $\boldsymbol{a l} .{ }^{(15)}$ designed a study to assess left ventricular (LV) mass in patients with diabetes mellitus (DM) using 2-dimensional echocardiography (2DE). The study included 165 patients divided into 3 equal groups: I: Included patients with DM only, II: Included patients with hypertension only and III: Included patients with both. Additional 35 normal subjects were added as control group. They concluded that DM is an independent risk factor for the increased LV mass and impaired systolic function regardless association with hypertension or not ${ }^{(\mathbf{1 5})}$.

Ostrowska et al. ${ }^{(16)}$ in a cross-sectional, multicenter study, used seven ECG criteria in order to detect LVH: 1) the Sokolow-Lyon voltage, 2) the Gubner voltage, 3) the criterion of the R wave amplitude on the leads V5-V6 and 4) aVL, 5) the gender specific Cornell voltage and 6) product, and 7) the Romhilt-Estes point score. They enrolled 1001 patients (48.5\% women, $51.5 \%$ men, mean age $65 \pm 11$ years) into the study. At least one ECG-LVH criterion was met in $20.0 \%(n=200)$ of the study participants. The ECG-LVH diagnosis was the most common when using the Romhilt-Estes point score ( $\mathrm{n}=$ $138 ; 13.8 \%)$. The corresponding prevalence rates for the Cornell voltage, the Cornell product, the $\mathrm{R}$ wave amplitude on the lead aVL, the SokolowLyon voltage, the Gubner voltage and the $\mathrm{R}$ wave amplitude on the leads V5-V6 criteria were 5.5\% $(\mathrm{n}=55), 5.2 \%(\mathrm{n}=52), 3.2 \%(\mathrm{n}=32), 2.2 \%(\mathrm{n}=$ $22), 1.9 \%(\mathrm{n}=19)$ and $1.3 \%(\mathrm{n}=13)$ respectively. Subsequently, the prevalence of the three most frequently used in clinical practice electrocardiographic criteria for LVH (the Sokolow-Lyon voltage, the Cornell voltage and the Romhilt-Estes point score) was analyzed. At least one of them was fulfilled in 185 ECGs. All three criteria at the same time were met only in 5 ECGs (2.7\% of 185). Two and only one out of three criteria were fulfilled in $20(10.8 \%)$ and 160 $(86.5 \%)$ ECGs respectively. And thus further studies are needed to compare diagnostic values of ECG-LVH criteria with imaging methods ${ }^{(16)}$.

As regards the accuracy of electrocardiography for detecting left ventricular hypertrophy by comparing it with the standard imaging modalities, there were multiple different studies in this topic.

Our results correlate with Peguero et $a l^{(5)}$ who tested a new method to improve the diagnostic performance of the electrocardiogram. The study was divided into 2 groups, a test and a validation cohort. In the 
test cohort, 94 patients were analyzed, including 47 with the diagnosis of hypertensive crisis and 47 with normal blood pressure at admission. Echocardiography was used to estimate the left ventricular mass index. The proposed ECG criteria involved measuring the amplitude of the deepest $\mathrm{S}$ wave (SD) in any single lead and adding it to the $S$ wave amplitude of lead V4 (SV4). Currently accepted LVH ECG criteria such as Cornell voltage and Sokolow-Lyon were used for comparison. The validation cohort consisted of 122 consecutive patients referred for an echocardiogram regardless of the admitting diagnosis. The results were that the SD was the most accurate single lead measurement for the diagnosis of LVH. When both cohorts were analyzed, the SD SV4 criteria outperformed Cornell voltage with a significantly higher sensitivity (62\% [95\% confidence interval [CI]: $50 \%$ to $72 \%$ ] vs. $35 \%$ [95\% CI: $24 \%$ to $46 \%$ ]). The specificities of all the criteria were $90 \%$, with no significant difference among them. They concluded that the proposed criteria for the ECG diagnosis of LVH improved the sensitivity and overall accuracy of the test ${ }^{(5)}$.

Our results correlate with the results of the cross-sectional study by Patted $\boldsymbol{e t}$ al. ${ }^{\left({ }^{(17)}\right.}$ in which a total of 400 patients with age $>30$ years having hypertension were studied. All the patients were subjected to ECG and 2D echo. In this study majority $(73.5 \%)$ of the patients were males and male to female ratio was 2.77:1. Most of the patients were aged between 61 to 70 years $(38.50 \%)$ and the mean age was $63.79 \pm 10.36$ years. Based on 2D echocardiography, LVH was diagnosed in $48 \%$ of the patients. Based on, Peguro-lo-presti, Cornell Voltage and Sokolow-Lyon criteria $30.50 \%, 24.50 \%$ and $21 \%$ of the patients were diagnosed to have $\mathrm{LVH}$ respectively. Of the 192 patients, one hundred and four (104) patients were diagnosed to have LVH based on Peguro-lo-presti criteria with strong agreement $(\mathrm{p}<0.001)$ between Peguro-lo-presti criteria and 2D echocardiograpgy for the diagnosis of $\mathrm{LVH}$ with sensitivity of $54.17 \%$. Also using Cornell Voltage criteria 76 out of 192 were diagnosed to have LVH and the sensitivity was $39.58 \%$ and using Sokolow-Lyon criteria, 56 out of 192 were diagnosed to have $\mathrm{LVH}$ with sensitivity of 29.17\%. The Peguero-Lo Presti ECG criteria yielded higher sensitivity $(54.17 \%)$ and specificity (91.35\%) in the diagnosis of LVH in patients with hypertension. They concluded that Peguero-Lo Presti criteria has higher sensitivity and specificity in the ECG diagnosis of LVH compared to Sokolow-Lyon and Cornell voltage criteria considering LV mass index by $2 \mathrm{D}$ Echocardiography as reference standard ${ }^{(17)}$.

In the study of Ang et al $^{(4)}$, a total of 241 consecutive patients with angiographically confirmed CAD were prospectively recruited and 11 ECG criteria were assessed on each subject and compared with the presence or absence of LVH on echo. Individual sensitivity, specificity, positive predictive value and negative predictive value were calculated for each ECG LVH criteria. The prevalence of echo $\mathrm{LVH}$ in the entire CAD population was $43 \%$. All the proposed ECG criteria were poor at identifying echo LVH. The Cornell product yielded the highest rate of change value but still missed up to $80 \%$ of the echo LVH cases. They concluded that in a group of stable, treated angina patients, ECG is an unreliable method of identifying LVH. As LVH is very common in this patient population, screening by means of echo might be indicated. This will enable intensified efforts to ensure LVH regression, which is associated with reduction in both cardiovascular morbidity and mortality ${ }^{(4)}$.

Hameed et $\boldsymbol{a l} .^{(18)}$ determined the sensitivity and specificity of electrocardiographic criteria for the assessment of left ventricular hypertrophy by comparing it with the gold standard of echocardiography. Fifty clinically diagnosed patients of LVH were included in this collaborative study. ECG of the patients were recorded and Romhilt-Estes point score calculated. This was followed by echocardiography and left ventricular mass and left ventricular mass index was calculated. It was found that Romhilt-Estes point score system of ECG had a sensitivity of $35 \%$ and specificity $90 \%$. It was concluded that the sensitivity of ECG is low in detecting $\mathrm{LVH}$, however, sensitivity can be increased by combining Sokolow Lyons voltage criteria and Cornell voltage criteria with Romhilt-Estes point score. ECG is however still recommended as a routine investigation because of its cost effectiveness and easy availability ${ }^{(18)}$.

LVH is mainly determined by an increase in left ventricular mass, which can be estimated by the electrical voltage changes detected on the surface electrocardiogram. This principle makes the electrocardiogram an 
acceptable surrogate to detect changes in left ventricular mass ${ }^{(5)}$.

However, the cardiac electrical voltage does not exclusively depend on the amount of myocardium. But, it is dependent on active and passive electrical properties of the heart and torsum. These in turn are modified by influencing factors such as distance of left ventricular cavity electrode, the location of the surface electrode, individual antrophometric differences, conduction abnormalities, fibrosis of the myocardium, and lung pathology ${ }^{(\mathbf{1 9})}$.

In addition, it has been described that the ECG voltage may vary significantly from day to day, between patients, or even within the same patient ${ }^{(20)}$.

All of these factors may attenuate the reproducibility of the test, leading to diagnostic errors. Given the aforementioned pitfalls, measurement of the maximum voltage increase in any single lead would be more sensitive in identifying an increase in the ventricular mass, rather than using any fixed lead criteria.

The LV geometry of concentric LVH was represented in a higher prevalence $(23 \%)$ in our study.

This finding is correlated to CAD population studies by Ang et al. (4) which showed a higher prevalence of concentric LV geometry.

The criteria used by the investigators for defining concentric LVH was the same as our criteria which a RWT $>0.42^{(14)}$.

Also our finding is similar to the population studies by Ghali $\boldsymbol{e t}$ al. ${ }^{(11)}$ which showed also a higher prevalence of concentric LV geometry. However the criteria used by these investigators for defining concentric $\mathrm{LVH}$ was a RWT $>0.45$.

It is worth noting that $27 \%$ of our study population had a previous history of MI and importantly, no infarcts were large enough to result reduced LVEF.

It is also worth noting that not all of our patients were at target BP. EUROASPIRE, the European Society of Cardiology Survey of Secondary Prevention of Coronary Heart Disease, shows that many patients with CAD in the real world fail to achieve target BP. This is sometimes called therapeutic inertia ${ }^{(21)}$.

Overall, this makes our study representative of real-world patients with CAD.

\section{CONCLUSION}

Also, this study appreciates the use of ECG to detect LVH in CAD patients especially in the centers where the echocardiography is not accessible. It seems reasonable to use routinely several ECG criteria for detection of LVH.

\section{REFERENCES}

1. Brown DL (2009): Effect of left ventricular hypertrophy on long-term survival of patients with coronary artery disease following percutaneous coronary intervention. Heart International, 4(1):1-9.

2. Bauml MA, Underwood DA (2010): Left ventricular hypertrophy: an overlooked cardiovascular risk factor. Cleve Clin $\mathbf{J}$ Med., 77(6): 381-7.

3. Abdi-Ali A, Miller RJ, Southern $D$ et al. (2018): LV mass independently predicts mortality and need for future revascularization in patients undergoing diagnostic coronary angiography. JACC Cardiovascular Imaging., 11(3):423-33.

4. Ang DS, Ti LL and Struthers AD (2008): The electrocardiogram is an unreliable method of identifying left ventricular hypertrophy in stable, treated angina patients. Journal of Human Hypertension, 22(6):394.

5. Peguero JG, Presti SL, Perez J et al. (2017): Electrocardiographic criteria for the diagnosis of left ventricular hypertrophy. Journal of the American College of Cardiology, 69(13):1694-703.

6. Okin PM, Hille DA, Kjeldsen SE et al. (2017): Combining ECG Criteria for Left Ventricular Hypertrophy Improves Risk Prediction in Patients With Hypertension. Journal of the American Heart Association, 6(11): 57-64.

7. Sokolow M, Lyon TP (1949): The ventricular complex in left ventricular hypertrophyas obtained by unipolar and limb leads. Am Heart J., 37: 161-186.

8. Padaki S, Dambal A (2017): SokolowLyon voltage and cornell voltage criteria in the diagnosis of left ventricular hypertrophy in obese individuals. Int J Clin Exp Physiol., 4:129-32. 
9. Romhilt DW, Estes EH (1968): Pointscore system for the ECG diagnosis of left ventricular hypertrophy. Am. Heart J., 75:75-92.

10. Lang RM, Badano LP, Mor-Avi V et al. (2015): Recommendations for cardiac chamber quantification by echocardiography in adults: an update from the American Society of Echocardiography and the European Association of Cardiovascular Imaging. European Heart Journal-Cardiovascular Imaging, 16(3): 233-71.

11. Ghali JK, Liao Y, Simmons B et al. (1992): The prognostic role of left ventricular hypertrophy in patients with or without coronary artery disease. Annals of Internal Medicine, 117(10):831-6.

12. Zabalgoitia $\mathrm{M}$, Berning $\mathrm{J}$, Koren $\mathrm{MJ}$ et al. (2001): Impact of coronary artery disease on left ventricular systolic function and geometry in hypertensive patients with left ventricular hypertrophy (the LIFE study). The American Journal of Cardiology, 88(6):646-50.

13. East MA, Jollis JG, Nelson CL et al. (2003): The influence of left ventricular hypertrophyon survival in patients with coronaryartery disease: do race and gender matter? Journal of the American College of Cardiology, 41(6):949-54.

14. Ang DS, Pringle SD and Struthers AD (2007): The cardiovascular risk factor, left ventricular hypertrophy, is highly prevalent in stable, treated angina pectoris. Am J Hypertens., 20(10): 1029-1035.
15. Anwar AM, Mostafa MM and Kholiefy AM (2009): Impact of Diabetes Mellitus on Left Ventricular Mass in Hypertensive and Normotensive Patients. The Egyptian Society of Cardiology Board of Directors, 306:30-45.

16. Ostrowska M, Bellwon J, Koziński M et al. (2016): Prevalence of electrocardiographic left ventricular hypertrophy among patients with coronary artery disease and diabetes mellitus. Medical Research Journal, 1(1):1-9.

17. Patted SV, Porwal SC, Ambar SS et al. (2018): Assessment of Peguero Lo-Presti Criteria for Electrocardiographic Diagnosis of LVH in Indian Subjects. Journal of Indian College of Cardiology, 8(4):187-90.

18. Hameed W, Razi MS, Khan MA et al. (2005): Electrocardiographic diagnosis of left ventricular hypertrophy: comparison with echocardiography. Pak J Physiol., 1(1):35-8.

19. Bacharova L, Ugander M (2014): Left ventricular hypertrophy: the relationship between the electrocardiogram and cardiovascular magnetic resonance imaging. Ann. Non-invasive Electrocardiol., 19:524533.

20. Hancock EW, Deal BJ, Mirvis DM et al. (2009): Electrocardiogram changes associated with cardiac chamber hypertrophy. J Am Coll Cardiol., 53:9921002.

21. Okonofua EC, Simpson KN, Jesri A et al. (2006): Therapeutic inertia is an impediment to achieving the Healthy People 2010 blood pressure control goals. Hypertension, 47(3):345-51. 